\title{
Performance of binary accelerator system on natural rubber compound
}

\author{
Ihda Novia Indrajati*, Indiah Ratna Dewi \\ Center for Leather, Rubber and Plastics, Jl. Sokonandi No. 9, Yogyakarta 55166, Indonesia \\ *Corresponding author. Tel. +62274512929, Fax. +62274563655 \\ E-mail: i-novia@kemenperin.go.id
}

Submitted: 16 July 2018

Revised: 20 November 2018

Accepted: 21 November 2018

\begin{abstract}
Accelerator system provides different response onto the rubber compound, and in turn influences its final properties. Accelerators, such as 2,2'-Dithiobis (benzothiazole) (MBTS), N-Cyclohexylbenzothiazole-2Sulfenamide (CBS) and diphenyl guanidine (DPG), has been selected for the study. Response of paired accelerator, MBTS/DPG and CBS/DPG in various ratio, on natural rubber (NR) compound was evaluated. Rheological properties and cure characteristics of the compounds were analyzed using Mooney viscometer and moving die rheometer (MDR) typically. Results findings showed that incorporation of DPG into the system has increased the viscosity of the compound and effected the molecular weight during the process. Further, the addition of DPG also shortened the induction period by reducing the scorch time $\left(\mathrm{ts}_{2}\right)$ and decreasing the cure time $\left(\mathrm{t}_{90}\right)$. Binary paired accelerator resulted in poor flow characteristic as a result of strong domination of elastic element. In general, the CBS-based system provided more balance characteristic than those of MBTS-based.
\end{abstract}

Keywords: Accelerator, flow property, Mooney viscosity, natural rubber

\section{INTRODUCTION}

Rubber is converted to a valuable product with excellent properties through several processing steps, i.e. compounding, forming and vulcanization. Compounding and forming processes are dominated by shearing force. Even though the operating temperature is below the vulcanization temperature, but shearing action during processing tends to generate heat. Attention should be taken in order to avoid the defect because excessive heat will bring to a premature vulcanization. Good flow property of rubber compound is also needed to ensure all mold cavities are completely fulfilled. One useful method for assessing this property is the Mooney viscosity measurement, in which it represents the rubber viscosity in low shear rate. This method is quite easy and quick to conduct, and thus it is widely used for processability evaluation in the factories (Kondo, 2014). Moreover, Mooney viscosity provides information related to the flow curve of the rubber compound (Zheleva, 2013).

Vulcanization becomes the determining step in rubber processing since it converts plastic- uncured- into elastic-cured rubber through the formation of three dimensional networks. This greatly affects the final properties of rubber product. Various vulcanizing systems are established nowadays, but sulfur vulcanization becomes the most widely used. Earlier, vulcanization using sulfur alone was inefficient because it took several hours to be completed. The discovery of accelerator in 1930 (Maciejewska et $a l ., 2013$ ) and introduction of zinc oxide and fatty acid as activator had shortened the vulcanization period, from hours into minutes. Types and concentrations of accelerator give direct influence on scorch safety and curing time of a rubber compound. Scorch safety is related to the allowable heat history of a rubber compound during the consecutive process. Thus, the knowledge of the response of each class of accelerator becomes mandatory. Frequently, a vulcanization system utilizes one or more accelerators simultaneously. The mixed system is reported to be more advantageous since it provides synergism activity to vulcanization process (Alam et al., 2014). Several studies on 
binary accelerator system had proven positive effect on sulfur vulcanization. Marykutty et al. (2003) employed thiourea derivate in combination with diphenylguanide (DPG) in natural rubber. Kamoun et al. (2009) studied the effect of a novel binary accelerator on curing characteristic and mechanical properties. Alam et al. (2014) published their work on synergism effect of thiuram disulfide and dibenzothiazyl disulfide in natural rubber vulcanization. The similar publication was made by Indrajati \& Sholeh (2014), using a combination of MBTS/ZDEC in natural rubber/ethylenepropylene-diene monomer blends. Ahsan et al. (2015) were experiencing with MBTS/DPG, MBTS/ZMBT and MBTS/ZMBT/DPG system on natural rubber. Most of those studies are emphasized on the curing characteristic, mechanical or thermal properties. None of them evaluates compound viscosity and flow properties during processing. This is a valuable information needed for forming step.

This present study employs the accelerator pairs, to evaluate their performance in natural rubber compounds. MBTS and CBS in combination with DPG are used as accelerator system with certain amount. The effect of accelerator pairs on Mooney viscosity, curing characteristic and flow property at a fixed angle will be monitored.

\section{MATERIALS AND METHODS \\ Materials}

Natural rubber (NR) grade SIR 20 was supplied by local industry in Indonesia (PTPN).
Carbon black N-330 and N-660 both are supplied by OCI Korea. $\mathrm{ZnO}$ Indoxide was purchased from Bratachem, Indonesia. Aflux 42M (Rhein Chemie) was used as processing promoter and antioxidant

2,2,4-Trimethyl-1,2-

Dihydroquinoline (TMQ) (Kemai). Accelerators used in this experiment consisted of 2,2'Dithiobis(benzothiazole) (MBTS) (Shandong Sianxian), diphenyl guanidine (DPG) (Shandong Shianxian), N-Cyclohexylbenzothiazole-2Sulfenamide (CBS) (Northeast). The accelerator properties are provided in Table 1. Sulfur was SP325 (Miwon). N-(cyclohexylthio)pthalimide (CTP) was used as a pre-vulcanization inhibitor. Maleated Castor Oil (MACO) used as a plasticizer was prepared by our team according to pervious work (Indrajati \& Dewi, 2017).

\section{Compound Preparation}

The performance of binary accelerator system on NR compounds was evaluated using two basic accelerator systems, i.e. MBTS or CBS in combination with DPG. Three sets of accelerator systems were chosen, set 1: MBTS or CBS alone (single accelerator), set 2: MBTS or CBS combined with DPG in a fixed loading, and set 3: MBTS or CBS combined with DPG with increased loading of MBTS or CBS (for detail see Table 2). NR and the additives were compounded using two roll mill following composition as described in Table 2. Once compounded, the rubber compounds were soaked into cold water for $5 \mathrm{~min}$ to terminate the vulcanization which might be proceeded, then stored in a conditioned room for $24 \mathrm{~h}$.

Table 1. Properties of accelerator types used in the experiment.

Accelerator type
No. $\begin{aligned} & \text { 2-2' Dithiobenzothiazole } \\ & \text { (MBTS) }\end{aligned}$
2. $\begin{aligned} & \mathrm{N} \text {-cyclohexyl benzothiazole 2- } \\ & \text { sulfenamide (CBS) }\end{aligned}$




\section{Mooney Viscosity Measurement}

Mooney viscosity (MV) was measured using MonTech Mooney Viscometer MV 3000. The large rotor was applied with the speed of $2 \mathrm{rpm}$ $(0.21 \mathrm{rad} / \mathrm{sec})$. The temperatures at upper and lower die were maintained at $130 \pm 0.03{ }^{\circ} \mathrm{C}$. Samples were prepared using sample cutter, then placed in lower die. Mooney viscosity was expressed in term $\mathrm{ML}(1+4)$ that means 1-minute preheating and 4-minutes viscosity testing. The tests carried out in duplicate. The averaged value was then determined and reported. The rate of material flow during declining period as determined by regression. The decline period is ranging between the first reduction of Mooney torque after the initial peak reached and the final torque or ML $(1+4)$. If the decline period is expressed as equation (1) obtained from regression, then the flow rate is defined as the 1st derivative of $y=f(x)$ as expressed in equation (2).

$$
\begin{aligned}
& y=f(x) \\
& y^{\prime}=\frac{d y}{d x}
\end{aligned}
$$

\section{Curing Characteristic}

Scorch time $\left(\mathrm{ts}_{2}\right)$, optimum curing time $\left(\mathrm{t}_{90}\right)$, cure rates, viscous (S") and elastic (S') torques data were obtained by Moving Die Rheometer Gotech M-3000A. The samples were tested at 130 and $180^{\circ} \mathrm{C}$ within fixed angle and frequency of 3 deg. and $100 \mathrm{cps}$, respectively. The data obtained from this experiment consisted of elastic torque $\left(\mathrm{S}^{\prime}\right)$, viscous torque (S"), scorch time $\left(\mathrm{ts}_{2}\right)$, optimum curing time $\left(\mathrm{t}_{90}\right)$ and cure rate $(\mathrm{CR})$. Minimum and maximum elastic torque were expressed as ML and MH, respectively. Reversion resistance of each accelerator set was determined using $\mathrm{R}_{300}$, the percentage of reversion degree after a period of $300 \mathrm{~s}$, calculated from the time reaching maximum torque $\mathrm{MH}$, as stated by Formela et al. (2015). $\mathrm{R}_{300}$ was calculated in accordance with Equation (3),

$R_{300}=\frac{M H-M_{300}}{M H} \times 100 \%$

where, $\mathrm{MH}$ is the maximum rheometer torque, $\mathrm{M}_{300}$ is the torque at $300 \mathrm{~s}$ after $\mathrm{MH}$ reached. The reversion rate was determined by the slope of the decline torque after $\mathrm{MH}$ reached (Boonkerd et al., 2016).

\section{RESULTS AND DISCUSSION \\ Mooney Viscosity}

Mooney viscosity measurement is based on shear deformation mode. Figure 1 depicts the Mooney curve of all rubber samples. It is clearly seen that all the curves exhibit typical Mooney curve, in which torque has sharply risen to a maximum value (peak A) at the beginning, and then decrease gradually until reaching a minimum value (point B). Sharp rise is caused by the stress which is developed straight after deformation. The following gradual decline region indicates the polymer is started to flow.

Table 2. Compounds formulation (phr).

\begin{tabular}{lrrrrrr}
\hline & \multicolumn{7}{c}{ Sample ID } \\
\hline \multirow{2}{*}{ Ingredients } & $\mathrm{N} 1$ & $\mathrm{~N} 2$ & $\mathrm{~N} 3$ & $\mathrm{~N} 4$ & $\mathrm{~N} 5$ & $\mathrm{~N} 6$ \\
\cline { 2 - 7 } SIR 20 & 100.0 & 100.0 & 100.0 & 100.0 & 100.0 & 100.0 \\
ZnO & 5.0 & 5.0 & 5.0 & 5.0 & 5.0 & 5.0 \\
Aflux 42 M & 1.5 & 1.5 & 1.5 & 1.5 & 1.5 & 1.5 \\
N-330 & 20.0 & 20.0 & 20.0 & 20.0 & 20.0 & 20.0 \\
N-660 & 15.0 & 15.0 & 15.0 & 15.0 & 15.0 & 15.0 \\
MACO & 5.0 & 5.0 & 5.0 & 5.0 & 5.0 & 5.0 \\
TMQ & 2.0 & 2.0 & 2.0 & 2.0 & 2.0 & 2.0 \\
6PPD & 1.0 & 1.0 & 1.0 & 1.0 & 1.0 & 1.0 \\
MBTS & 1.2 & 1.0 & 1.2 & 0.0 & 0.0 & 0.0 \\
CBS & 0.0 & 0.0 & 0.0 & 1.2 & 1.0 & 1.2 \\
DPG & 0.0 & 0.2 & 0.2 & 0.0 & 0.2 & 0.2 \\
Sulfur & 1.0 & 1.0 & 1.0 & 1.0 & 1.0 & 1.0 \\
PVI & 0.1 & 0.1 & 0.1 & 0.1 & 0.1 & 0.1 \\
\hline
\end{tabular}




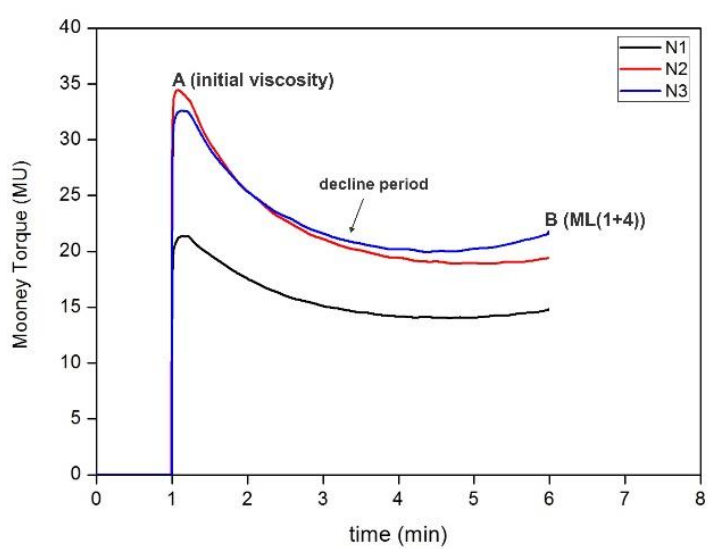

(a)

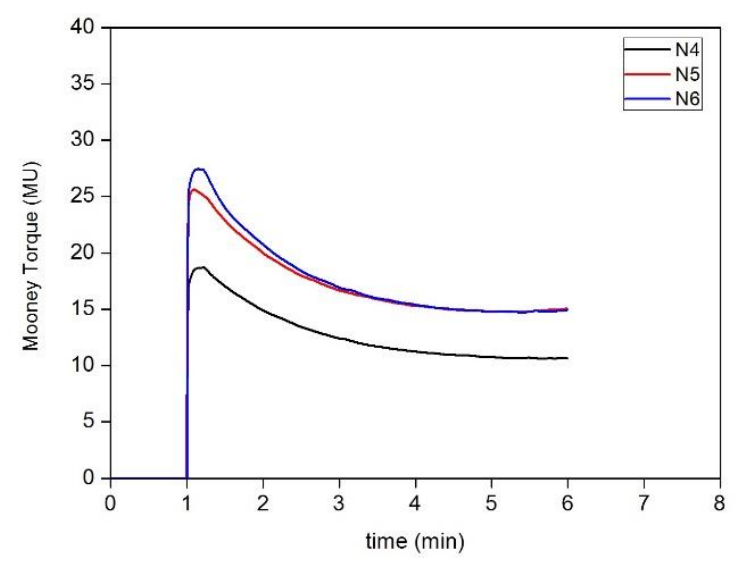

(b)

Figure 1. Mooney viscosity of rubber samples, a) MBTS-based, b) CBS-based.

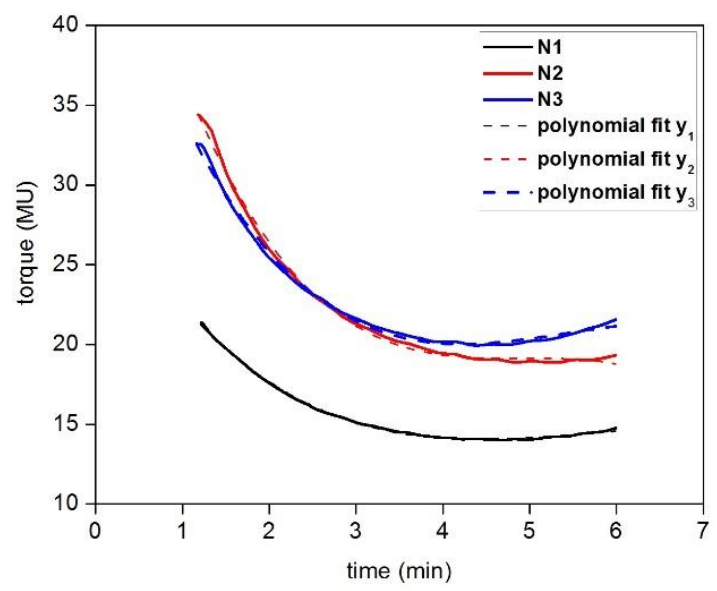

(a)

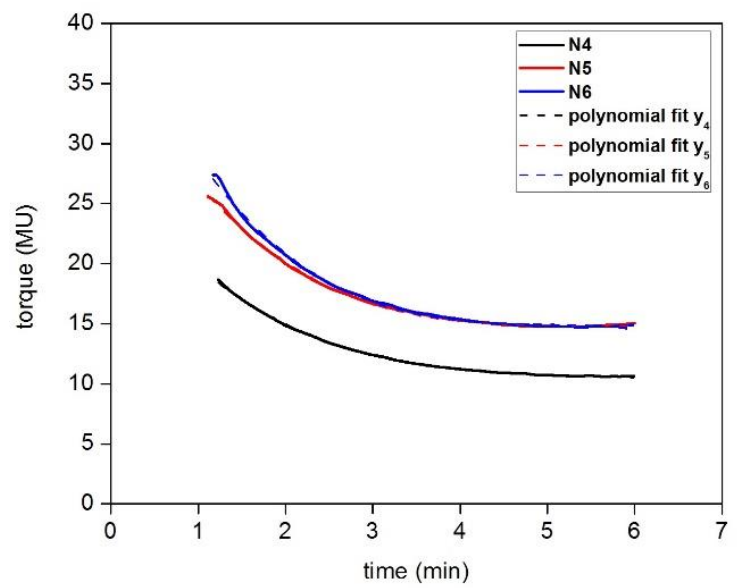

(b)

Figure 2. Curve fitting of declining period of Mooney curve a) MBTS-based, b) CBS-based.

Table 3. Regression equations.

\begin{tabular}{ccc}
\hline Sample ID & Regression Equation & $\mathrm{R}^{2}$ \\
\hline N1 & $y_{1}=-0.1022 x^{3}+1.7215 x^{2}-9.2289 x+30.048$ & 0.9988 \\
N2 & $y_{2}=-0.2881 x^{3}+4.2201 x^{2}-20.530 x+52.305$ & 0.9965 \\
N3 & $\mathrm{y}_{3}=-0.2008 x^{3}+3.2611 x^{2}-16.800 x+47.033$ & 0.9962 \\
N4 & $y_{4}=-0.1113 x^{3}+1.7246 x^{2}-9.1335 x+27.252$ & 0.9993 \\
N5 & $y_{5}=-0.1553 x^{3}+2.4213 x^{2}-12.6370 x+36.964$ & 0.9988 \\
N6 & $y_{6}=-0.2164 x^{3}+3.2023 x^{2}-15.9580 x+41.732$ & 0.9972 \\
\hline
\end{tabular}

Under the shearing action, the linkage of carbon-polymer or carbon-carbon is probably broken down, thus initiating flow (Kondo, 2014). According to Malac (2011), peak A represents the initial viscosity of the rubber compound, while point $B$ is the ML(1+4). The initial viscosity of a rubber compound is a function of its green strength (Malac, 2011). Green strength is defined as the resistance of uncured rubber against deformation.In the processing perspective, the level of compound viscosity should be adjusted in which compound can be processed without any defect or consuming much energy. Incorporation of DPG increases the Mooney viscosity as indicated in Figure 1. According to Kaewsakul et al. (2013), in filled compound, higher compound viscosity is attributed to the hydrodynamic effect, interaction of filler-filler or filler-polymer, and the possibility of premature crosslinking. Hydrodynamic effect occurs when a nondeformable solid is added into rubber matrix so that the deformable rubber portion will be reduced (Intiya et al., 2017). The hydrodynamic effect in this experiments can be neglected because it is 
probably contributed to the better interaction between filler-filler and filler-rubber. In the carbon black filled compound, DPG may infiltrate into the outer region of carbon black particles. Two aromatic rings in DPG molecules (Table 1) and the solid state are the steric hindrances that prevent its penetration into inner region of carbon black. Thus, an outer layer surrounding carbon black particles is formed and reduces the agglomeration. This will lead to a better carbon black dispersion level in rubber matrix (Le et al., 2011). However, rising the concentration of MBTS or CBS along with fixed DPG concentration is insensitive to the viscosity changes as it remains constant. In general, CBSbased accelerator provides lower viscosity than MBTS-based. This is probably related to the synergism effect of accelerator pairs and their adsorption effect on carbon black surface.

The gradual decline period of Mooney curve provides a rough description of the molecular weight changes that commences rubber compound to flow under deformation action. In turn, it is related to the allowable deformation forces and rate that is worked onto rubber compound during processing. The flow rate can be assessed by curve fitting of the decline period (regression).

Figure 2 clearly depicts that all the curves are in well-agreement to third-order polynomial regression since all the fitted model give $\mathrm{R}^{2} \approx 0.99$ (Table 3). Figure 3 depicts the trend of the rate of decline period. Both accelerator pairs exhibit lower flow rate than single accelerators. This is perhaps related to their high viscosity. A sharp increase is occurred at early stage and then followed by gradual increase. However, single accelerators tend to increase linearly. The addition $0.2 \mathrm{phr}$ of DPG has markedly increased the rate in MBTS-based, and it gives the lowest rate among the accelerator sets. Further, it has been observed that addition of MBTS reduces the flow rate. In CBS-based, the rate is increased upon the addition of DPG. Further addition of CBS tends to increase it. Thus, a careful consideration should be taken to treat this trend because the mismatch viscosity of rubber compound will generate problem in the subsequent processes. Too low viscosity may cause the compound to stick on the rolls or screw during processing. In contrast, very high viscosity compound is hard to process and consumes more energy. However, CBS-based accelerators give lower flow rate within the same accelerator concentration.

\section{Curing Characteristic}

Figure 4 illustrates the relationship the torque changes (curing curve) during the MDR measurement and all extracted data from curing curve are presented in Table 4 . All of the samples show the typical rheometer curing curve for accelerated sulfur vulcanization. It comprises three regions that reflect the reaction stages taking place during vulcanization, i.e. induction period, curing period and over cure as depicted in Figure 4a (Rabiei \& Shojaei, 2016).

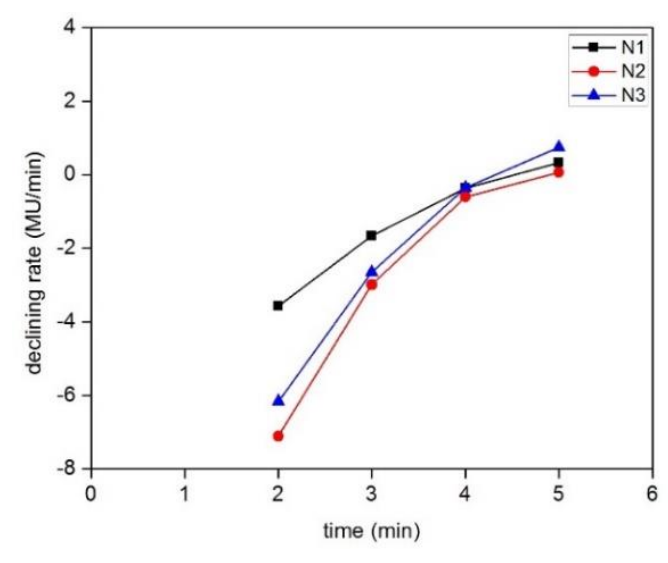

(a)

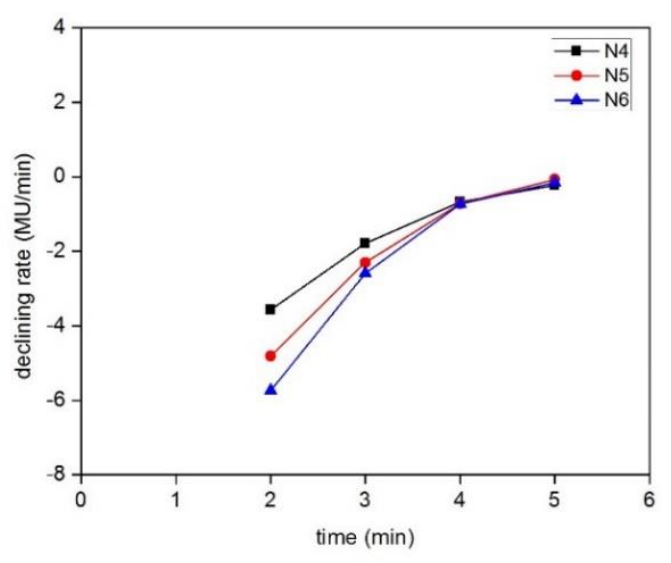

(b)

Figure 3. The rate of declining period of Mooney curve a) MBTS-based, b) CBS-based. 


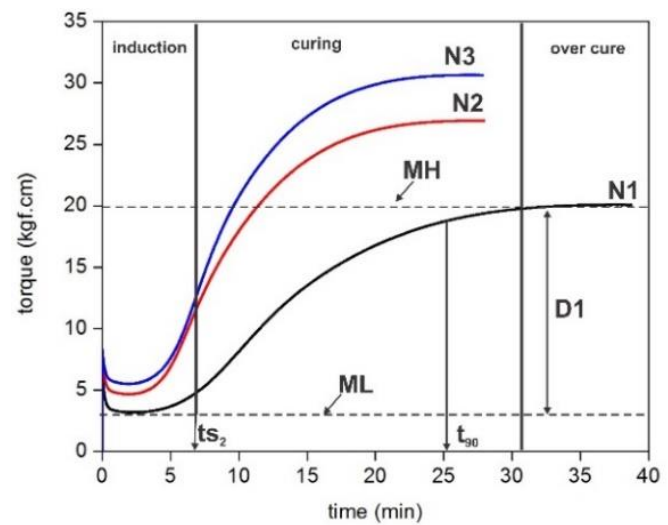

(a)

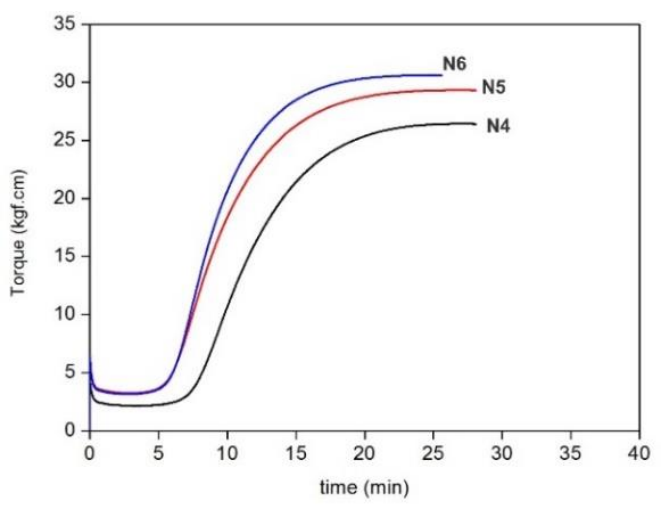

(b)

Figure 4. Curing curve (torque vs time) a) MBTS based, b) CBS based.

The induction period is the time when the vulcanization reaction has not been started yet. Physical linkages are mostly formed in this period as a result of the interaction between rubber and filler particles, and the chain entanglement as well. Scorch time $\left(\mathrm{ts}_{2}\right)$ and minimum torque (ML) are often used to characterize the induction period. Scorch time gives a sign for the vulcanization onset. Moreover, ML also corresponds to the viscosity of the uncured rubber compound (Ahmadi \& Shojaei, 2013).

In this experiment, ML is observed to increase upon the incorporation of DPG for both accelerators system as depicted in Figure 4. This increasing could probably be attributed to the better interaction between rubber-filler and fillerfiller which is promoted by DPG. Further addition of MBTS or CBS gives the dilution effect observed by a slight reduction of ML. This trend is agreed to the Mooney viscosity mentioned earlier. Chemical crosslinks are formed during the curing period, at which the vulcanization reaction takes place. The crosslink formation is monitored by the increasing of the rheometer torque, until reaching a maximum value $(\mathrm{MH})$. The torque differences (MH-ML) is a useful tool to trace the progress of the crosslink development (Rabiei \& Shojaei, 2016). It represents the net chemical crosslink that is formed during the curing period. Binary accelerators result in higher crosslink density than of a single accelerator. The crosslink density of CBS-based accelerator is somewhat higher than of MBTS-based in the same set of accelerator pair. This is probably attributed by the synergism effect of the accelerator pairs that provides higher crosslinks. Another important parameter obtained from the rheometer test is optimum cure time $\left(\mathrm{t}_{90}\right)$. It is the time needed for the cured rubber to reach $90 \%$ of the maximum achievable torque. $t_{90}$ is practically used to cure the rubber compound, in which it achieved optimum properties (Khimi \& Pickering, 2014). MBTS alone and CBS alone result in higher t90 $_{90}$ than of pair accelerator as seen in Table 4 . Addition of DPG into the system reduces $t_{90}$.

As mentioned elsewhere, vulcanization reaction is taken place through several steps. Vulcanization is initiated by the formation of sulfur active species, then followed by their interaction with unsaturation sites of rubber molecule chains to generate crosslink precursor. These crosslink precursors subsequently react with additional unsaturation sites on rubber resulting in polysulfidic crosslink. The last stage is crosslink maturation in which the polysulfidic crosslinks may undergo desulfuration or degrade to cyclic sulfides or other main-chain modifications. These may cause long-term deterioration on rubber vulcanizates. Among these steps, the formation of active sulfurating species is the critical step. This species is formed during the induction period, in which accelerator chemistry plays major roles (Anandhan et al., 2012). The action of accelerator pairs has shortened the induction period, confirmed by low scorch time $\left(\mathrm{ts}_{2}\right)$ as seen in Table 4. 
Table 4. Cure characteristics.

\begin{tabular}{|c|c|c|c|c|c|c|c|}
\hline Samples ID & $\begin{array}{c}\mathrm{ts}_{2} \\
(\mathrm{~min})\end{array}$ & $\begin{array}{c}\mathrm{t}_{90} \\
(\mathrm{~min})\end{array}$ & $\begin{array}{c}\text { MH } \\
\text { kgf.cm }\end{array}$ & $\begin{array}{c}\text { ML } \\
\text { kgf.cm }\end{array}$ & $\begin{array}{c}\text { MH-ML } \\
\text { kgf.cm }\end{array}$ & $\begin{array}{l}\mathrm{R}_{300} \\
(\%)\end{array}$ & $\begin{array}{l}\text { Reversion } \\
\text { rate }\end{array}$ \\
\hline \multicolumn{8}{|l|}{$130^{\circ} \mathrm{C}$} \\
\hline $\mathrm{N} 1\left(\mathrm{~S} / \mathrm{A}^{*}=0.83\right)$ & 7.22 & 25.28 & 23.24 & 2.59 & 20.65 & 0 & 0 \\
\hline $\mathrm{N} 2(\mathrm{~S} / \mathrm{A}=0.83)$ & 6.57 & 17.37 & 26.93 & 4.66 & 22.27 & 0 & 0 \\
\hline $\mathrm{N} 3(\mathrm{~S} / \mathrm{A}=0.71)$ & 5.25 & 16.67 & 28.49 & 4.00 & 24.49 & 0 & 0 \\
\hline $\mathrm{N} 4(\mathrm{~S} / \mathrm{A}=0.83)$ & 7.93 & 17.55 & 26.43 & 2.11 & 24.32 & 0 & 0 \\
\hline N5 (S/A=0.83) & 6.22 & 15.53 & 29.32 & 3.21 & 26.11 & 0 & 0 \\
\hline N6 $(\mathrm{S} / \mathrm{A}=0.71)$ & 6.18 & 14.23 & 30.60 & 3.12 & 27.48 & 0 & 0 \\
\hline \multicolumn{8}{|l|}{$180^{\circ} \mathrm{C}$} \\
\hline $\mathrm{N} 1(\mathrm{~S} / \mathrm{A}=0.83)$ & 0.43 & 0.98 & 19.48 & 1.60 & 17.88 & 43.48 & 0.035 \\
\hline $\mathrm{N} 2(\mathrm{~S} / \mathrm{A}=0.83)$ & 0.42 & 0.80 & 15.38 & 2.51 & 12.87 & 39.34 & 0.024 \\
\hline $\mathrm{N} 3(\mathrm{~S} / \mathrm{A}=0.71)$ & 0.38 & 0.78 & 24.16 & 2.58 & 21.58 & 40.48 & 0.028 \\
\hline $\mathrm{N} 4(\mathrm{~S} / \mathrm{A}=0.83)$ & 0.50 & 0.88 & 21.82 & 1.78 & 20.04 & 44.78 & 0.037 \\
\hline $\mathrm{N} 5(\mathrm{~S} / \mathrm{A}=0.83)$ & 0.43 & 0.78 & 24.98 & 2.05 & 22.93 & 42.75 & 0.033 \\
\hline $\mathrm{N} 6(\mathrm{~S} / \mathrm{A}=0.71)$ & 0.45 & 0.77 & 26.41 & 1.90 & 24.51 & 40.29 & 0.029 \\
\hline
\end{tabular}

${ }^{*} \mathrm{~S} / \mathrm{A}=$ sulfur to accelerator ratio

Further addition of MBTS greatly affects $\mathrm{ts}_{2}$. However, further addition of CBS causes little change on it. MBTS and CBS give different vulcanization reaction mechanism. Upon heating, MBTS will interact to molecular sulfur $\left(\mathrm{S}_{8}\right)$ to form accelerator polysulfide. The presence of $\mathrm{ZnO}$ leads to the formation of complex with accelerator polysulfide (structure type I) as depicted in Figure 5. If ligand L such as amines or carboxylate ions are also present in the system, the structure of $\mathrm{Zn}$ - accelerator complex turns into $\mathrm{Zn}$ /amines-accelerator complex as in Figure 6 (structure type II). Both structures are activesulfurating species that subsequently react with rubber molecule to form crosslink precursor.

Different from MBTS, CBS does not readily react with $\mathrm{ZnO}$ to form $\mathrm{Zn}$-accelerator complex. The possible way to form $\mathrm{Zn}$-accelerator complex is through the reaction between $\mathrm{MBT}$ and $\mathrm{ZnO}$. MBT is initially generated during thermal decomposition of CBS as expressed on reaction 1 (Figure 7). Once formed, MBT is immediately converted to MBTS according to reaction 2 (Figure 8). Thus, the key reactions of sulfenamide (CBS) accelerator in induction period are the thermal decomposition of CBS into MBT and the reaction of remaining CBS with MBT to form MBTS (Anandhan et al., 2012). If the formation of MBTS is delayed, the subsequent reactions will also be delayed too. In another word, the length of the induction period is greatly affected by the<smiles>c1ccc2sc(SSc3nc4ccccc4s3)nc2c1</smiles>

Figure 5. Zn-accelerator complex (type I).<smiles>IC[As](CI)(Sc1nc2ccccc2s1)Sc1nc2ccccc2s1</smiles>

Figure 6. Zn-accelerator complex with ligand (type II).

thermal stability of CBS, hydrolysis and/or reduction (Heideman et al., 2004).

Thermal decomposition of CBS also releases amines that possibly form type II structure $\mathrm{Zn}$ accelerator complexes (Figure 6). This chelation has better stability to the accelerator complex (Joseph et al., 2015) and increases the activity of the complex in conjunction to stearic acid or another fatty acid (Peter et al., 2016; Heideman et al., 2004).But, the results show CBS alone provides longer scorch time than MBTS alone. This could be related to the presence of the prevulcanization inhibitor (PVI) in the formulation that causes competition reactions. PVI reacts with MBT formed during CBS decomposition, depletes its number that converted into MBTS (Joseph et al., 2015). 


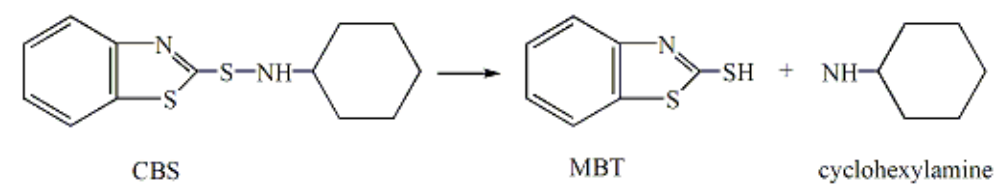

Figure 7. Thermal decomposition reaction of CBS.

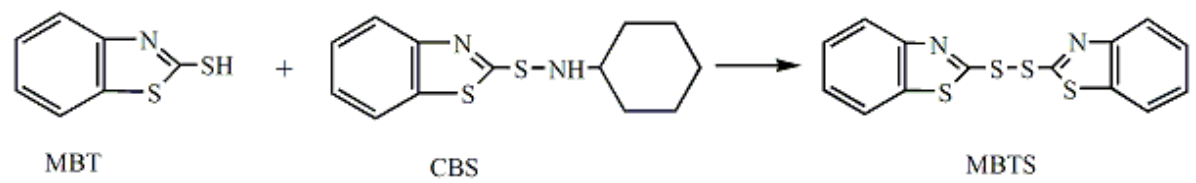

Figure 8. The conversion reaction of MBT into MBTS.

The reaction between MBT and PVI is proceeded faster than of reaction between MBT and CBS to form MBTS (Ghosh et al., 2003). Thus, the delayed formation of MBTS will prolong the induction period with the so-called "scorch delayed" action.

In accelerator pair, DPG activates the primary accelerator (MBTS or CBS). Similar to DPG, amines released by CBS may form the type II structure of Zn-accelerator complex. The enhanced numbers of type II structure automatically increase the reactivity and stability the complex that leads to higher rate of vulcanization reaction. Amines also facilitate the conversion of elemental sulfur $\left(\mathrm{S}_{8}\right)$ and/or polysulfide into active open chain sulfur through ring opening reaction. Amines might attack polysulfidic crosslink, either by direct reaction or by $\mathrm{HS}^{-}$generation (Heideman et al., 2004).

Curing rate curves of both systems (Figure 9) show a bell-type curve with the peak is being the cure rate maximum $\left(\mathrm{CR}_{\max }\right)$. The cbs-based system results in higher $\mathrm{CR}_{\max }$ than of MBTSbased system at the same concentration. MBTS based system (Figure 9) shows a longer tail indicating that the reaction proceeds longer towards completeness. DPG has increased the cure rate for both systems. This probably related to the amines that released by DPG or even CBS that leads to type II $\mathrm{Zn}$-accelerator complex (with ligand).

Reversion commonly occurs in natural rubber when it is vulcanized at elevated temperature or for a prolong heating. It is indicated by a gradual decline in elastic torque (S') beyond the maximum elastic torque ( $\left.\mathrm{S}^{\prime} \mathrm{MH}\right)$ and rises in viscous torque above minimum viscous torque (S"ML) (Ohnuki, 2015). Furthermore, Ohnuki (2015) explains that reversion indicates a fatal drawback since it exhibits an increase in hysteresis loss. Formela et al. (2015) measured the degree of reversion at $300 \mathrm{~s}$ after $\mathrm{MH}$ reached $\left(\mathrm{R}_{300}\right)$ to predict the aging resistance of vulcanizates at elevated temperature. In this experiment, both systems show reversion effect at elevated vulcanization temperature $\left(180^{\circ} \mathrm{C}\right)$ with $\mathrm{R}_{300}$ (Table 4). Single accelerator results in higher reversion compared to the paired accelerator. But, the addition of DPG into the accelerator system gives positive effect by lowering the reversion rate. According to Boonkerd et al. (2016), reversion is strongly related to the type and the number of crosslinks formed during vulcanization. Usually, crosslinks with shorter S$\mathrm{S}$ bonds (mono- or di-sulfidic) are more thermally stable at elevated temperature. These crosslinks are formed when the ratio of sulfur to accelerator (S/A) is low or, in other words, the concentration of sulfur is lower than of accelerator.

\section{Compound Flow Characteristic}

The flow of rubber compound is important to evaluate. It will affect the molding process and subsequently the vulcanization. Flow characteristic is strongly related to the viscosity at any given state. Being a viscoelastic material, the viscosity of rubber is rather complex because it has elastic and viscous elements which are presented on certain ratio at the same time and position. Viscous element facilitates the compound to flow, whereas the elastic element tends to hinder it. The flow characteristic of rubber compounds can be assessed through evaluating the viscous (S") and elastic (S') torque obtained from MDR rheograph. Figure depicts the plot of S"/S' ratio versus time for all rubber samples. The curve is divided into two regions that are separated by the transition line at $S^{\prime \prime} / S^{\prime}=1$ (dashed line). The area above this line (area 1) represents the domination of the viscous element 
in which S" $>\mathrm{S}$ ', while the area below the transition line (area 2) shows the domination of elastic element. The time when the S"/S' curve crosses the transition line is correlated to the scorch time $\mathrm{ts}_{2}$, at which the vulcanization takes place.

Figure 10 clearly displays that both accelerator systems exhibit similar pattern. At early stage, viscous element shows its domination overall the system (shaded area). In this stage, rubber compound flows to fulfill the mold cavities. Higher viscous element provides better flow characteristic. Then, elastic element starts to take over the domination in the system by the time vulcanization reaction proceeded. At this stage, compound is nearly stopped to flow. Therefore, better flow characteristic is an important factor to obtain perfect product shape and dimension. Compared to the paired accelerator, the single accelerator has wider area 1 that means to have better compound flow characteristic.

Introduction of DPG into the system significantly decreases this area. It is probably as a result of better interaction between rubber-filler

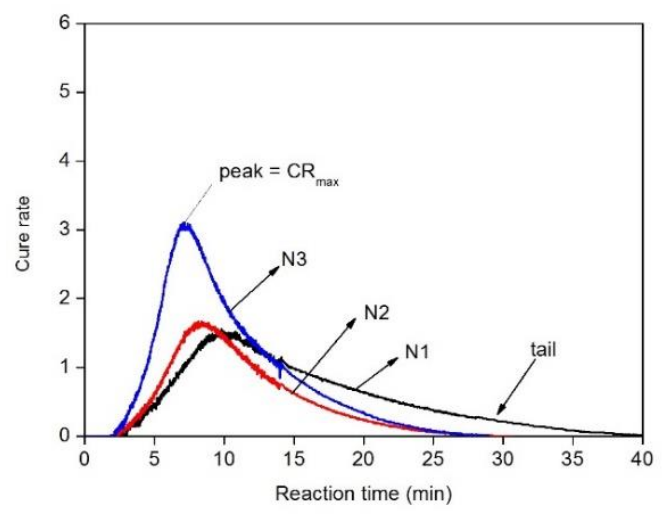

(a) and filler-filler noticed by higher ML. All of the curve parts of MBTS/DPG systems are laid on below the transition line (Figure 10) that exhibits strong domination of elastic element since at the beginning. This could generate problems during compound processing. Since elastic elements hinder the flow, then more energies are needed in the molding process. Moreover, poor flow characteristic also affects the possibilities of rejected product caused by uneven mold filling. Further, it also negatively impacts in extrusion process due to increased die swell. The curve deviates substantially when MBTS/DPG ratio is $1.0 / 0.2(\mathrm{~N} 2)$ compared to those of MBTS/DPG $1.2 / 0.2(\mathrm{~N} 3)$. The deviation may be correlated to the crosslink density of the respect compound (Figure 4a) that causes elastic element presents in less amount than the viscous element. Thus, the rubber compound will be easier to flow and broaden the $\mathrm{S}$ "/S curve. This finding is not observed when CBS/DPG is used (N5 and N6) because of similar resulted crosslink density (Figure 4b).

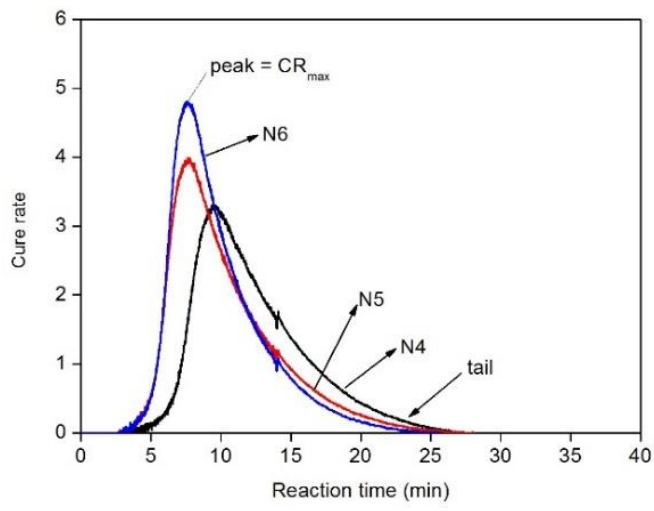

(b)

Figure 9. Curing rate curve, a) MBTS- b) CBS-based accelerator system.

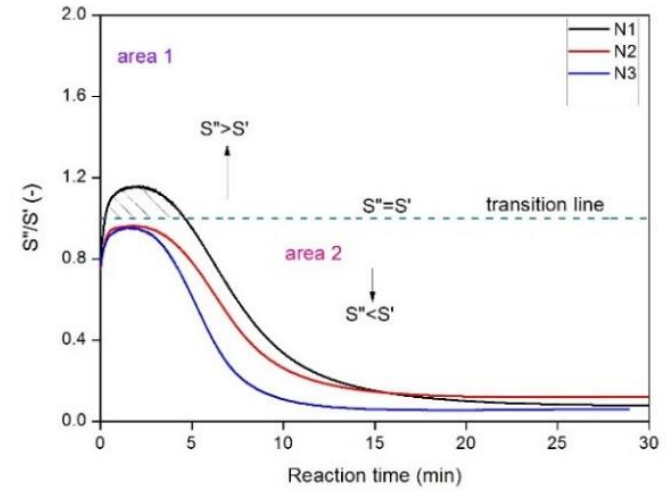

(a)

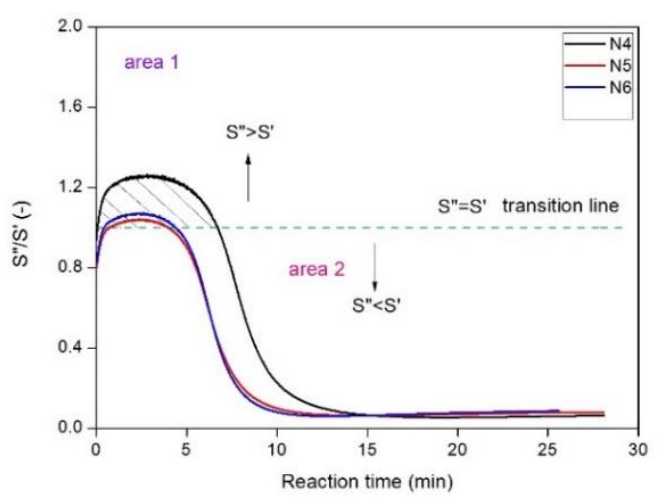

(b)

Figure 10. Ratio viscous to elastic torque (S"/S'), a) MBTS-based, b) CBS-based. 


\section{CONCLUSIONS}

Performance of MBTS/DPG and CBS/DPG accelerator systems in natural rubber compound are evaluated through assessing the Mooney viscosity, curing characteristics and flow property at a fixed angle. Accelerator type affects the Mooney viscosity, in which single accelerator (MBTS or CBS alone) provides lower Mooney viscosity compared to paired accelerators. In the same concentration, MBTS-based systems result in higher Mooney viscosity than of CBS-based systems. DPG plays a role in providing interaction between filler-filler and rubber-filler that leads to increasing in Mooney torque. High Mooney viscosity is correlated to the domination of elastic element (S') at early stage of vulcanization. The molecular weight changes are represented by the declining period of Mooney curve. Compounds with single accelerator are tended to decline linearly, while paired accelerator make a sharp increase at the beginning and then followed by a gradual decrease. Elastic rheometric torques (ML and $\mathrm{MH}$ ) were also affected by the accelerator type and concentration. Paired accelerators resulted in higher ML than those of single accelerators. When the concentration of the primary accelerator (MBTS or CBS) increased, ML tended to decrease. This finding was agreed to high Mooney viscosity of the rubber compound. MBTS-based system overall provided higher ML. Incorporation of DPG has raised the MH and so that the crosslink density represented by the torque differences (MH-ML). CBS alone showed the so-called delayed action as a result of $\mathrm{Zn} /$ amines-accelerator complex formation. The delayed action was not found in MBTS-based system. Addition of DPG has shortened scorch time $\left(\mathrm{ts}_{2}\right)$ and optimum cure time $\left(\mathrm{t}_{90}\right)$ for both accelerator systems. Both accelerator systems showed reversion phenomenon, but DPG has lowered the rate. Single accelerator resulted in better flow characteristic since viscous element shows their domination in the early stage of vulcanization. MBTS/DPG system provides poor flow characteristic because of the domination of elastic element since the beginning.

\section{ACKNOWLEDGEMENTS}

The authors are grateful to thank the head of the Center for Leather, Rubber and Plastics, Ministry of Industry for funding the research through DIPA 2016.

\section{REFERENCES}

Ahmadi, M., \& Shojaei, A. (2013). Cure kinetic and network structure of NR/SBR composites reinforced by multiwalled carbon nanotube and carbon blacks. Thermochimica Acta, 566, 238248. https://doi.org/10.1016/j.tca.2013.06.004

Ahsan, Q., Mohamad, N., \& Soh, T. C. (2015). Effects of accelerators on the cure characteristics and mechanical properties of natural rubber compounds. International Journal of Automotive and Mechanical Engineering, 12, 2954-2966. https://doi.org/10.15282/ijame.12.2015.12.0247

Alam, M. N., Mandal, S. K., Roy, K., \& Debnath, S. C. (2014). Synergism of novel thiuram disulfide and dibenzothiazyl disulfide in the vulcanization of natural rubber: Curing, mechanical and aging resistance properties. International Journal of Industrial Chemistry, 5(1), 1-11. https://doi.org/10.1007/s40090-014-0008-6

Anandhan, M., Kaisare, N. S., Kannan, K., \& Varkey, B. (2012). Population balance model for vulcanization of natural rubber with delayedaction accelerator and prevulcanization inhibitor. Rubber Chemistry and Technology, 85(2), 219243. https://doi.org/10.5254/rct.12.89971

Boonkerd, K., Deeprasertkul, C., \& Boonsomwong, K. (2016). Effect of sulfur to accelerator ratio on crosslink structure, reversion, and strength in natural rubber. Rubber Chemistry and Technology, 89(3), 450-464. https://doi.org/10.5254/rct.16.85963

Formela, K., Wąsowicz, D., Formela, M., Hejna, A., \& Haponiuk, J. (2015). Curing characteristics, mechanical and thermal properties of reclaimed ground tire rubber cured with various vulcanizing systems. Iranian Polymer Journal, 24(4), 289297. https://doi.org/10.1007/s13726-015-0320-9

Ghosh, P., Katare, S., Patkar, P., Caruthers, J. M., Venkatasubramanian, V., \& Walker, K. A. (2003). Sulfur vulcanization of natural rubber for benzothiazole accelerated formulations: From reaction mechanisms to a rational kinetic model. Rubber Chemistry and Technology, 76(3), 592693. https://doi.org/10.5254/1.3547762

Heideman, G., Datta, R. N., Noordermeer, J. W. M., \& van Baarle, B. (2004). Activators in accelerated sulfur vulcanization. Rubber Chemistry and Technology, 77(3), 512-541. https://doi.org/10.5254/1.3547834

Indrajati, I. N., \& Dewi, I. R. (2017). Performance of maleated castor oil based plasticizer on rubber: rheology and curing characteristic studies. IOP Conference Series: Materials Science and Engineering, 223, 12001. https://doi.org/10.1088/1757-899X/223/1/012001

Indrajati, I. N., \& Sholeh, M. (2014). Pengaruh rasio MBTS/ZDEC pada campuran karet alam dan etilen propilen diena yang dibuat dengan teknik 
kontrol migrasi curatives. Majalah Kulit, Karet, dan Plastik, 30(1), 43-52. https://doi.org/10.20543/mkkp.v30i1.124

Intiya, W., Thepsuwan, U., Sirisinha, C., \& Sae-Oui, P. (2017). Possible use of sludge ash as filler in natural rubber. Journal of Material Cycles and Waste Management, 19(2), 774-781. https://doi.org/10.1007/s10163-016-0480-5

Joseph, A. M., George, B., Madhusoodanan, K. N., \& Alex, R. (2015). Current status of sulphur vulcanization and devulcanization chemistry: Process of vulcanization. Rubber Science, 28(1), 82-119.

Kaewsakul, W., Sahakaro, K., Dierkes, W. K., \& Noordermeer, J. W. M. (2013). Optimization of rubber formulation for silica-reinforced natural rubber compounds. Rubber Chemistry and Technology, 86(2), 313-329. https://doi.org/10.5254/RCT.13.87970

Kamoun, M., Nassour, A., \& Michael, N. (2009). The effect of novel binary accelerator system on properties of vulcanized natural rubber. Advances in Materials Science and Engineering. https://doi.org/10.1155/2009/916467

Khimi, S. R., \& Pickering, K. L. (2014). A new method to predict optimum cure time of rubber compound using dynamic mechanical analysis. Journal of Applied Polymer Science, 131(6). https://doi.org/10.1002/app.40008

Kondo, H. (2014). Evaluation of rubber processing in unvulcanised rubber. International Polymer Science and Technology, 41(7), 51-58. https://doi.org/10.1177/0307174X1404100710

Le, H. H., Ilisch, S., Hamann, E., Keller, M., \& Radusch, H. J. (2011). Effect of curing additives on the dispersion kinetics of carbon black in rubber compounds. Rubber Chemistry and Technology, 84(3), 415-424. https://doi.org/10.5254/1.3592299
Maciejewska, M., Walkiewicz, F., \& Zaborski, M. (2013). Novel ionic liquids as accelerators for the sulfur vulcanization of butadiene-styrene elastomer composites. Industrial and Engineering Chemistry Research, 52(25), 8410-8415. https://doi.org/10.1021/ie303167z

Malac, J. (2011). Mooney viscosity, Mooney elasticity and processability of raw natural rubber. Journal of Material Science and Engineering with Advanced Technology, 3(1), 67-87.

Marykutty, C. V., Mathew, G., Mathew, E. J., \& Thomas, S. (2003). Studies on novel binary accelerator system in sulfur vulcanization of natural rubber. Journal of Applied Polymer Science, 90(12), 3173-3182. https://doi.org/10.1002/app.13023

Ohnuki, T. (2015). The vulcanizing system of diene rubber. International Polymer Science and Technology, 42(8), 39-46. https://doi.org/10.1177/0307174X1504200808

Peter, R., Sreelekshmi, R. V., \& Menon, A. R. R. (2016). Cetyltrimethyl ammonium bromide modified kaolin as a reinforcing filler for natural rubber. Journal of Polymers and the Environment, 1-9. https://doi.org/10.1007/s10924-016-0915-z

Rabiei, S., \& Shojaei, A. (2016). Vulcanization kinetics and reversion behavior of natural rubber/styrene-butadiene rubber blend filled with nanodiamond - The role of sulfur curing system. European Polymer Journal, 81, 98-113. https://doi.org/10.1016/j.eurpolymj.2016.02.021

Zheleva, D. (2013). An attempt for correlation between Mooney viscosity and rheological properties of filled rubber compounds. Journal of Chemical Technology and Metallurgy, 48(3), 241-246. 
